\title{
Standard Operating Procedure Optimization of Resource Level for Hospital Waste Handling Using Hybrid DES-ABM Simulation, Genetic Algorithm, and Goal Programming
}

\author{
Danica Virlianda Marsha ${ }^{1, *}$, Riyanarto Sarno ${ }^{1, *}$, Kelly Rossa Sungkono ${ }^{1, *}$ \\ ${ }^{1}$ Institut Teknologi Sepuluh Nopember, Surabaya, Indonesia \\ “Corresponding author.Email: nicavira@gmail.com, riyanarto@if.its.ac.id, kelly@its.ac.id
}

\begin{abstract}
The emergence of the Covid-19 pandemic has caused several changes in healthcare services carried out by hospitals. Covid-19 has caused increasing waste generated from medical activities and operational service activities, in which the Standard Operating Procedure (SOP) has been adjusted due to new regulations to prevent cross-contamination during this pandemic. The increasing number of wastes generated and changes in SOP could have impacted on spending more costs for processing medical waste caused by Covid-19 operational services and causes longer service time. The purpose of this study was to find the optimum value of resource level based on operational costs and service time from the medical waste handling developed with hybrid Discrete Event Simulation - Agent-Based Modelling (DES-ABM) to capture real-time events. To find optimum value, optimization techniques such as Genetic Algorithm and Goal Programming are also used. Optimization from this research results in 17 alternatives of resource level from a total of 100 generations and 20 initial design point. The best design point found could reduce the waiting time by 26.87 minutes, reduce completion time by 506.82 minutes, and reduce cost IDR117,144 from the initial resource level used by the hospital.
\end{abstract}

Keywords: hospital resource, optimization, simulation, waste

\section{INTRODUCTION}

Hospitals are one of the public services vital daily to act as a healthcare provider. Within the emergence of the Covid-19 pandemic started on March 2020[1], hospitals have to adjust their operating procedure to prevent cross-contamination by the waste produced. The Covid-19 pandemic, especially in Indonesia, is continuing to have an impact to the healthcare system and their waste management system. According to World Health Organization (WHO), waste produced from discarded materials have significantly increased. There is almost $50 \%$ increase in waste generation each month due to this situation. It is essential to analyse the potential of inefficiencies such as time and cost, occurred in waste handling process in hospital, and determine optimum resource level that could overcome the situation.

Hospital waste handling - or also known as hospital waste management system, is one of complex system that involves various resources and chain of activities. Simple analysis such as mathematical modelling alone is not sufficient to define relationship between their input and output [2]. One of popular method to portray such a complex system is a simulation. Numerous studies have used simulation to portray similar optimization problems, and proved that simulation is a powerful tool to solve optimization in factory flow problem[3], manufacturing[4], construction problem[5], supply chain[6], also other healthcare service unit such as emergency department[2], [7]-[10], bed capacity allocation[11], [12], and patient assignment[13].

Bedoya-Valencia and Kirac[2] have analyzed alternative resource allocation in hospital, especially in the emergency department using Discrete Event Simulation (DES) to determine various resource level and their impact to patient length-of-stay and time to be seen by a physician or physician assistant by utilizing scenarios. Zhang et. al performed simulation-based optimization to evaluate patient assignment to physicians and clinical units using DES with two alternatives of choices[13]. From those previously conducted research, a single model process[14] is used to represent actual system, in fact, in the actual system there could be more than one object involved. To overcome this limitation, multi-agent approach will be used in this research, therefore collaboration process model will certainly take place to portray the linkage between agents.

This research aims to find optimum resource level for waste handling system in hospital using simulation. 
To portray real time events, Agent-Based Modelling $(\mathrm{ABM})$ is also combined with DES, in consideration of the nature of agent behaviour in a complex system[15]. Multi agent is also used to give a better view of each type of agent and their performance in the system. System performance is obtained from simulations run from the model that generates event logs, and from these outputs, optimization with Genetic Algorithm [16] and Goal Programming[17] is performed to find optimum combination of resource level in a bigger design space.

\section{LITERATURE REVIEW}

\subsection{Previous Research}

The nature of the complexity of the system causes difficulty in determining function to be optimized, as it holds non-analytical, non-differentiable, and non-linear relationship that could only be evaluated within simulation[18]. Simulation could also cover for uncertainty factors[19].

Agent-Based Modelling (ABM) [20] is the most recent technique to develop model. Agent based modelling could give better sense at how the individual or agent affects system as a whole[21]. Combining DES with ABM could results in better, detailed model depiction of real world condition, where agent-based elements drive the model [22].

To perform optimization, DES is often used to perform planning of healthcare services[21]. A general simulation-based optimization framework has been developed[23], which uses simulation to find optimum value of the parameter settings. On the context of optimization, petri-nets based optimization[24] has been developed for business process. Other approach such as Goal Programming [4], [25], [26] and Stochastic Multicriteria Adaptability Analysis 2 (SMAA-2) [27] have been used to perform optimization. On high notes, Genetic Algorithm is one of most widely used algorithm to perform optimization[28], [29] in various problems. Genetic Algorithm is an algorithm developed by Goldberg[16], inspired by a theory from Charles Darwin of natural evolution to find optimum solution, where most fitted or adaptable individual survived and regenerate to produce offspring.

\subsection{Simulation}

Simulation is one of problem solving of complex system by recreating or imitating real world system[30]. It is considered a more flexible approach to solve complex problems which mathematical model formulation often fails to do. Simulation is done to perform experimental conditioning, without the need to do so in the actual system. This method is cost saving since changes are not required to be applied in real system to obtain experiment result. There are several approaches in modeling and simulation: Discrete Event Simulation (DES), Agent-Based Modelling (ABM), and dynamic system. One of the latest approaches emerged is $\mathrm{ABM}$, where $\mathrm{ABM}$ could define interaction and behavior in agent level.

\subsection{Optimization}

Optimization has been a widely studied as it plays an important role in various problem and various field of study. Optimization aims to find the best use of resource of situation - where this statement is relevant in almost every field. One practical area to implement optimization is time-cost optimization[4], [29], [31], [32]. The goal of this optimization is to find optimum trade-off from time and cost spent for a project or system. Optimization could be done by several method, like PERT and Goal Programming[25], and fuzzy goal programming to optimize time and cost[33]. Goal programming is one of the widely used methods, and Data Envelopment Analysis (DEA) is one of goal programming formulation that could be used to define system efficiency. DEA formulation follows the Equation introduced by Charnes, et al. [34].

\section{METHOD}

Waste handling in the observed hospital; hospital X, involves resources in the operational activities. Waste disposal in this hospital requires manpower, and material handling equipment. Based on the standard operational procedure for waste handling in hospital X, BPMN is created to ease the construction of the model, as seen on Figure 1. Variability of resource level and the impact to the system performance will be judged from four resource categories: cleaning service staff, incinerator operators, material handling trolley, and incinerator machine. These resources are chosen since they play important role in defining throughput of the waste handling system.

This research combines simulation and optimization techniques to define optimum resource level based on the calculation of waiting time, completion time, and operational cost, based on the framework as seen in Figure 2. The first step is to construct hybrid DES-ABM model to obtain event $\log$ s from simulation running. These event $\log$ s are later to be used to calculate cost per agent that passes the activity blocks in the model. Simulation will be run for each design point - that determine combination of resource level of each variable that represents resource in the system. This combination will be the initial population for Genetic Algorithm, which later be used to generate individuals and find the best individual of design point (DP). 


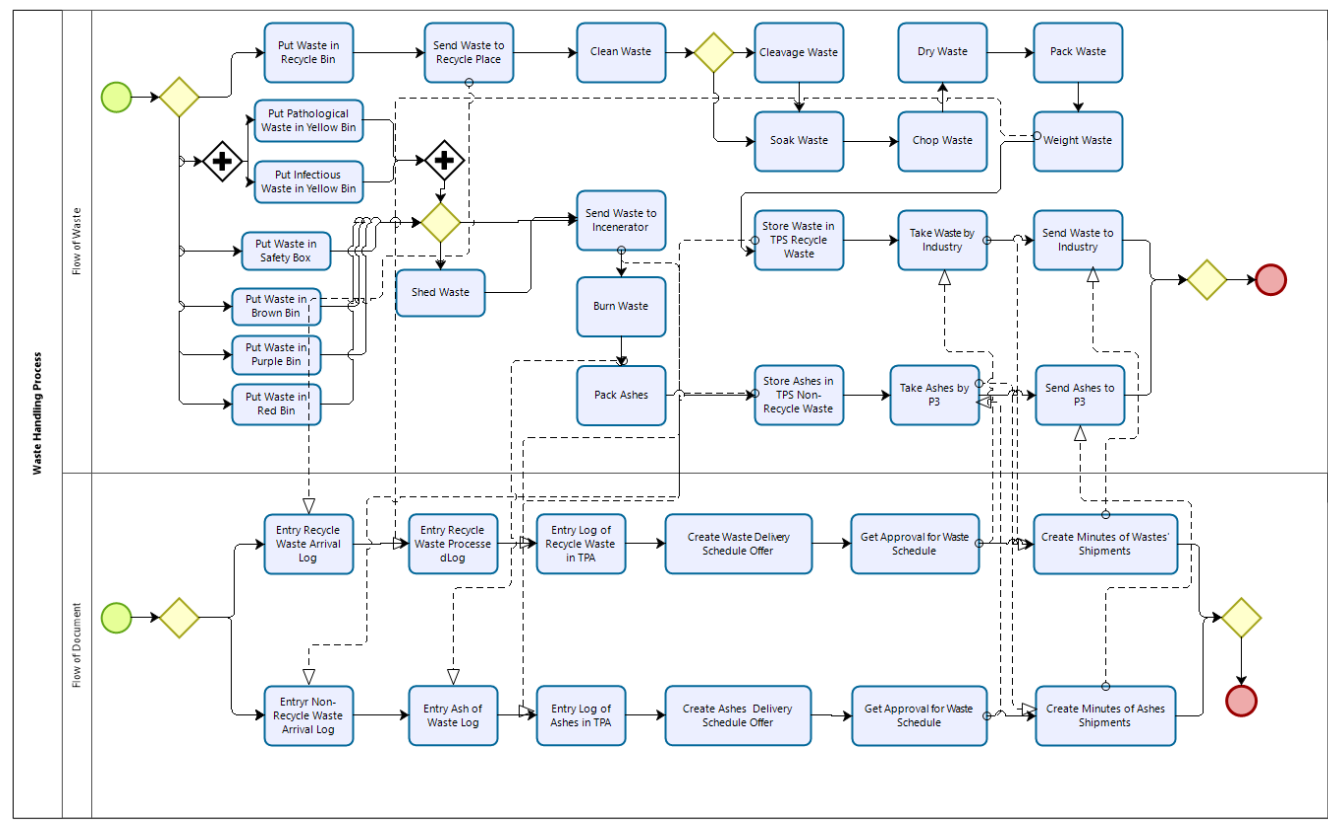

Figure 1 BPMN of waste handling system

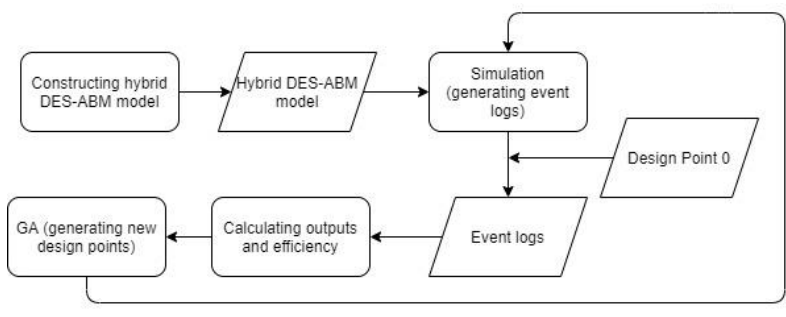

Figure 2 Research Framework

\subsection{Constructing hybrid DES-ABM model}

Model is constructed using AnyLogic software to portray the logical flow of process, using process modelling and agent library to combine DES and ABM as seen in Figure 3 and Figure 4. This hybrid DES-ABM includes resource pool which capacity could be adjusted. Waste handling system consists of 4 different resources: cleaning service staffs, incinerator operators, trolleys, and incinerators. This model initially set with resource pool capacity the same as actual resource level, and this design point of resource level will be referenced as design point 0 (DP0). The model then used to run simulation to capture daily events occurrence, using event logs generated after the simulation run.

\subsection{Simulation}

Simulation is set to generate daily event logs, and set to terminate in 30 days of simulation unit time. This could capture variability in daily event logs. Each design point will be run once to generate logs of 30 days. In each simulation, simulation parameter performed by resource capacity is changed to the value of each design point, so in total there is 20 simulations for initial population. Each simulation will generate event $\operatorname{logs}$, consisting of agent, agent type, block type, block, activity, start date, and stop date. Agent defines unique ID, which later could help to trace waste and related document since this model uses multi-agent approach. Start date and stop date shows the timestamp an agent entering and leaving particular block, later used to calculate length of stay of an agent in blocks to obtain activity cost.

\subsection{Calculating outputs and efficiency}

Costs are calculated per case from the event logs time stamp, by multiplying each activity cost per minute by length of stay in the activity block as follows on Eq. 1. Waiting time (WT), completion time (CT), and average cost of case (AC) will be the performance measure of each design point. Average cost of case is calculated from average value of cost per case, where cost per case is calculated by Eq. 1

Efficiency for each design point is calculated relative to other design point in the same population with DEA formulation. For the efficiency calculation, we need to transform WT, CT, and COC of each design point to the form of reduction of value relative to DP0 to transform formulation into maximization problem.

$$
\text { Cost per case }=\sum c_{n} \times t_{n}
$$

where:

$$
\begin{aligned}
& \text { Cost per case }=\text { cost spent per case } \\
& c_{n}=\text { cost per minute for activity } \mathrm{n} \\
& t_{n}=\text { length of stay in activity } \mathrm{n} \text { block }
\end{aligned}
$$




\subsection{Genetic Algorithm to define best resource level}

Genetic Algorithm is used to generate random individual known as design point in this research. Initial population is generated using design point DP1 representing combination of maximum resource level for each resource, decreasing in DP2, DP3, and so on. Each design point will be simulated using to generate another event $\log$ and calculate performance measures. For each design point, we run 30 simulations to generate
20 cases of each type of waste and recorded the value of waiting time, completion time, and cost per case. This resource level of design point will be referred as input variable $(\mathrm{X})$.

The next step of GA which is generating new design points will follow hybrid Data Envelopment Analysis (DEA)-GA developed by Lin et al. [34]. DEA is used to calculate efficiency of each design points. This is performed as a matrix operation to evaluate efficiency of each design points relative to another.

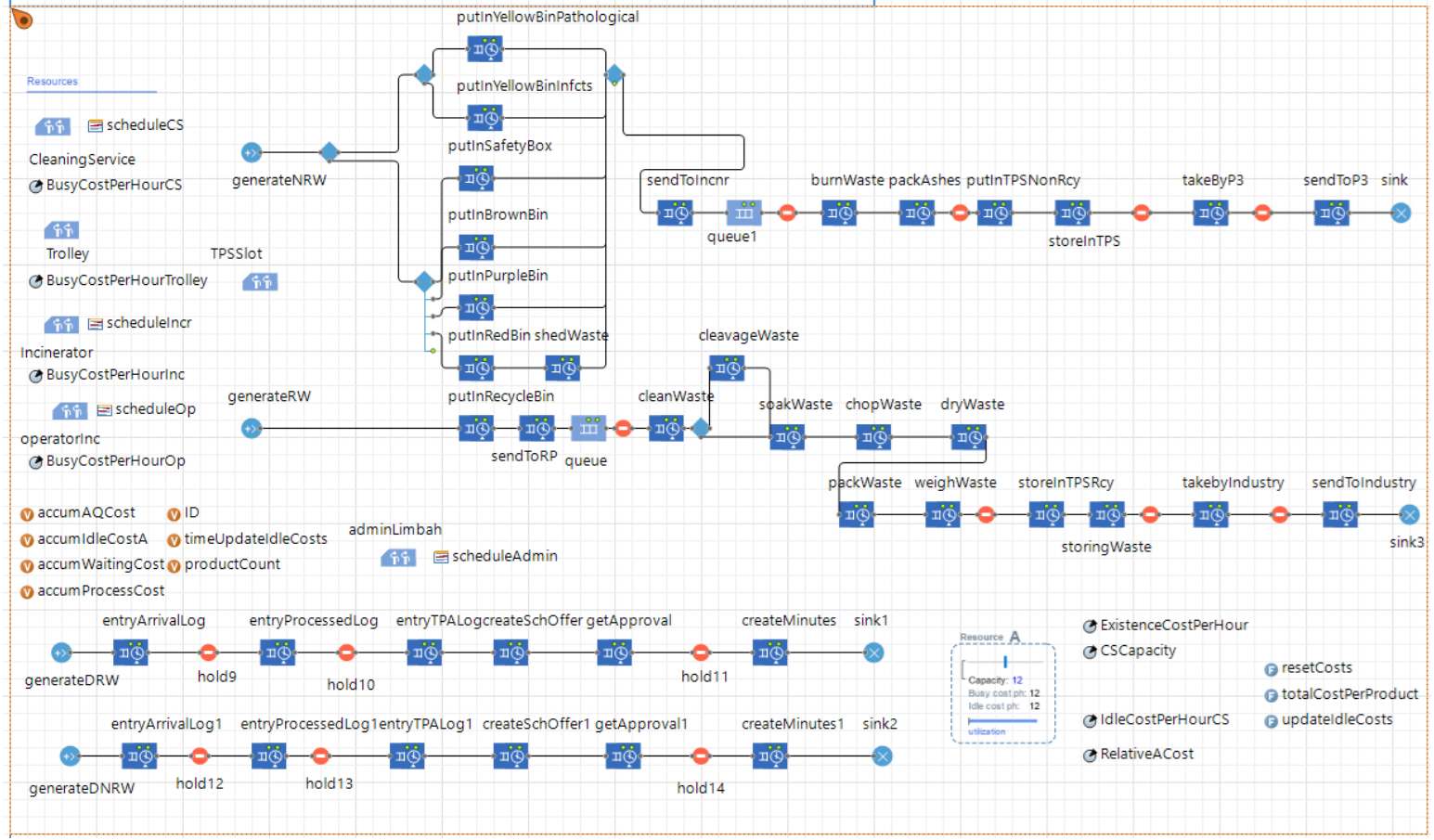

Figure 3 DES-ABM Model (1)

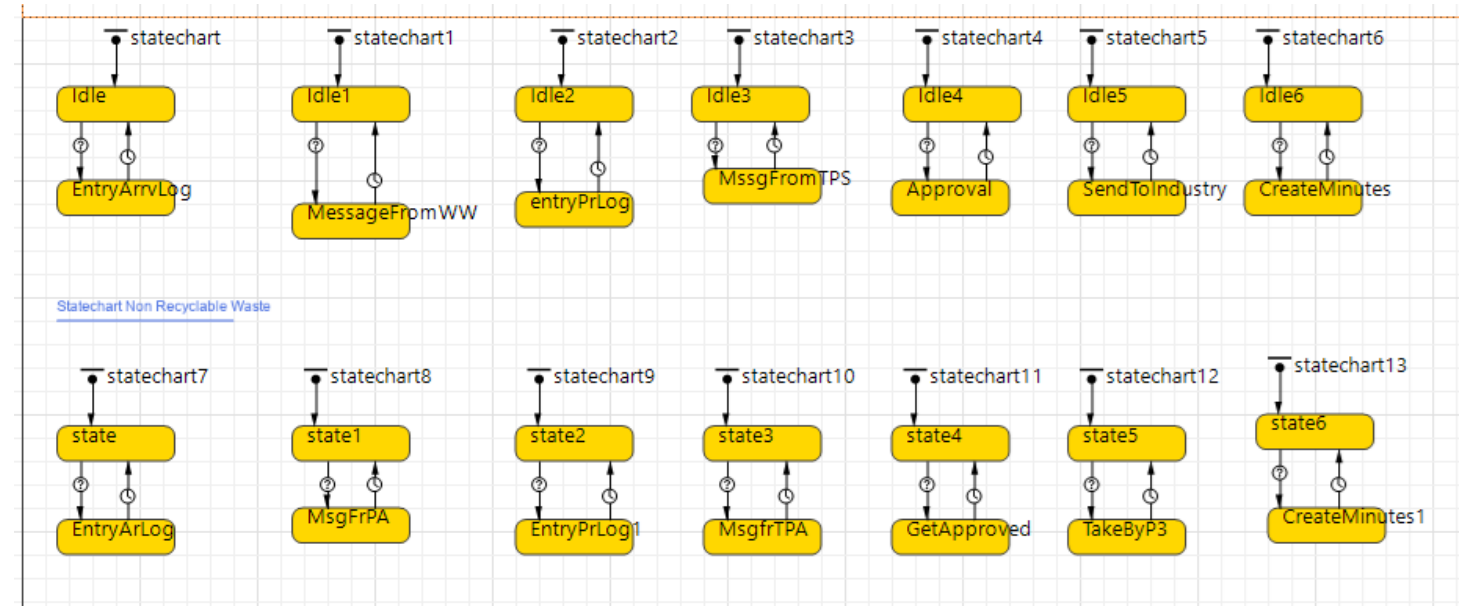

Figure 4 DES-ABM Model (2)

\section{RESULTS AND ANALYSIS}

Following the experimental steps of Genetic Algorithm and simulation, 100 generations are done to find the best design point of resource level. Design point with efficiency score of 1.00 is considered efficient, while design point that score efficiency point below 1.00 is considered inefficient. From this rule, 17 unique 
design points are found and considered efficient shown in Table 1. X variables represent input resource level: $\mathrm{X} 1$ for cleaning service staff, $\mathrm{X} 2$ for incinerator operator, X3 for trolley, and $\mathrm{X} 4$ for incinerator. $\mathrm{Y}$ variables represent output level: Y1 for waiting time, Y2 for completion time, and $\mathrm{Y} 3$ for cost per case.

Table 1. Efficient Design Points

\begin{tabular}{|c|c|c|c|c|c|c|c|}
\hline $\begin{array}{l}\text { Design } \\
\text { Point }\end{array}$ & X1 & $\mathrm{X} 2$ & $\mathbf{X 3}$ & X4 & Y1 & Y2 & Y3 \\
\hline 1 & 20 & 10 & 2 & 1 & 217.05 & 1115.28 & 275845 \\
\hline 2 & 30 & 15 & 2 & 2 & 192.17 & 1437.13 & 232109 \\
\hline 3 & 30 & 10 & 2 & 1 & 207.10 & 1282.82 & 232293 \\
\hline 4 & 30 & 10 & 2 & 2 & 194.08 & 1384.53 & 246919 \\
\hline 5 & 20 & 10 & 2 & 2 & 211.09 & 1109.12 & 254198 \\
\hline 6 & 20 & 10 & 5 & 2 & 190.15 & 1044.25 & 226288 \\
\hline 7 & 20 & 10 & 5 & 1 & 229.18 & 1473.47 & 234193 \\
\hline 8 & 20 & 15 & 2 & 2 & 221.22 & 1058.20 & 289493 \\
\hline 9 & 20 & 15 & 2 & 1 & 220.03 & 1477.28 & 248030 \\
\hline 10 & 30 & 15 & 5 & 2 & 192.038 & 1222.46 & 230292 \\
\hline 11 & 20 & 10 & 2 & 1 & 215.05 & 1115.28 & 275845 \\
\hline 12 & 15 & 10 & 2 & 1 & 229.08 & 1207.92 & 235501 \\
\hline 13 & 15 & 15 & 2 & 2 & 214.25 & 1204.00 & 239401 \\
\hline 14 & 15 & 15 & 2 & 1 & 219.91 & 1232.29 & 234029 \\
\hline 15 & 15 & 10 & 5 & 2 & 203.98 & 1208.88 & 241010 \\
\hline 16 & 15 & 10 & 5 & 1 & 217.04 & 1209.13 & 245022 \\
\hline 17 & 15 & 10 & 2 & 2 & 218.07 & 1213.24 & 240182 \\
\hline
\end{tabular}

From the result, the range for the minimum-maximum value of each output variable can be seen on Table 2 through Table 4. From these extreme design points, the optimum solution for waste handling resource level is represented by DP6, since this design point delivers minimum value of all performance measure.

Table 2. Extreme Design Point for Waiting Time

\begin{tabular}{|l|l|l|l|l|l|l|l|}
\hline DP & $\mathbf{X 1}$ & $\mathbf{X 2}$ & $\mathbf{X 3}$ & $\mathbf{X 4}$ & $\mathbf{Y 1}$ & Y2 & Y3 \\
\hline 6 & 20 & 10 & 5 & 2 & 190.15 & 1044.25 & 226288 \\
\hline 7 & 20 & 10 & 5 & 1 & 229.18 & 1473.47 & 234193 \\
\hline
\end{tabular}

Table 3. Extreme Design Point for Completion Time

\begin{tabular}{|l|l|l|l|l|l|l|l|}
\hline DP & $\mathbf{X 1}$ & $\mathbf{X 2}$ & $\mathbf{X 3}$ & $\mathbf{X 4}$ & $\mathbf{Y 1}$ & $\mathbf{Y 2}$ & $\mathbf{Y 3}$ \\
\hline 6 & 20 & 10 & 5 & 2 & 190.15 & 1044.25 & 226288 \\
\hline 9 & 20 & 15 & 2 & 1 & 220.03 & 1477.28 & 248030 \\
\hline
\end{tabular}

Table 4. Extreme Design Point for Cost

\begin{tabular}{|l|l|l|l|l|l|l|l|}
\hline DP & $\mathbf{X 1}$ & $\mathbf{X 2}$ & $\mathbf{X 3}$ & $\mathbf{X 4}$ & $\mathbf{Y 1}$ & $\mathbf{Y 2}$ & $\mathbf{Y 3}$ \\
\hline 6 & 20 & 10 & 5 & 2 & 190.15 & 1044.25 & 226288 \\
\hline 8 & 20 & 15 & 2 & 2 & 221.22 & 1058.20 & 289493 \\
\hline
\end{tabular}

For comparison, Goal Programming calculation alone is done to compare the performance between Genetic Algorithm and Goal Programming. Goal Programming model could be seen in Figure 5. Goal Programming calculation result shows that out of 17 unique design points, 16 design points are considered efficient and DP8 is considered inefficient. DP6 has minimum value on all output variables, with waiting time of 190.15 minutes, completion time of 1044.25 minutes, and costs IDR226,288.

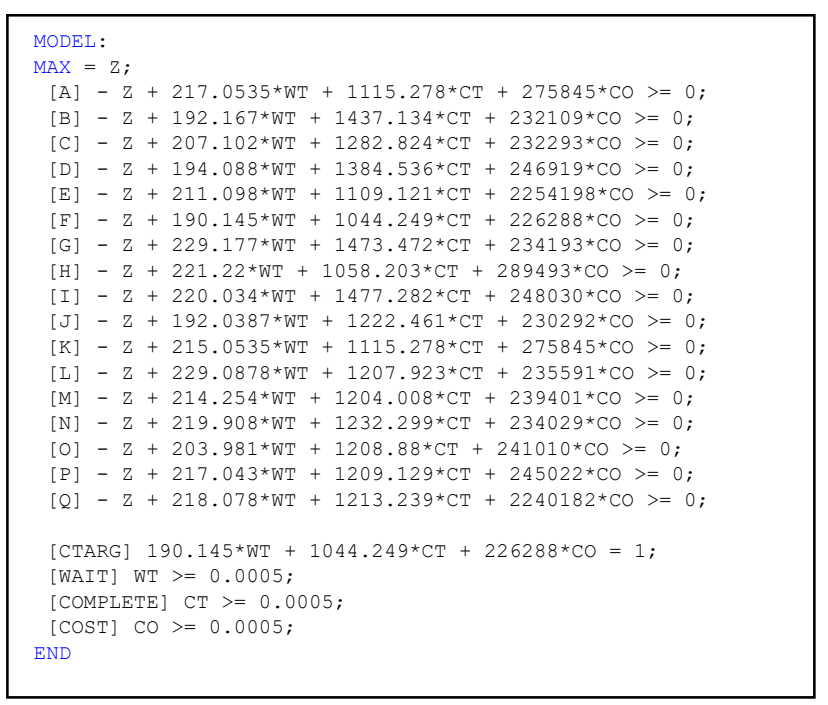

Figure 5 Goal Programming Source Code

Optimization from the Genetic Algorithm and Goal Programming results in the reduction of waiting time, completion time, and also cost for the waste handling system. Based on the result of design point 6 , utilizing 20 cleaning service workers, 10 incinerator operators, 5 trolleys, and 2 incinerators, results in reducing waiting time 26.87 minutes, reducing completion time 506.82 minutes, and reducing cost Rp117,144

Comparing performance measure of system of initial condition in DP0 and after optimization using GA and Goal Programming, result shows that in most efficient design points, waiting time is reduced. For completion time, all design points show significant reduction compared to DP0, and costs less than DP0 for all design points as shown in Figure 6 through Figure 8. DP6 is considered the most efficient. Based on the waiting time, there are few design points that is considered efficient but delivers longer waiting time than DP0, as seen on Figure 6. For completion time and cost, all design points managed to reduce the value than DP0, meaning that these alternatives could perform better in terms of completion time and cost than the initial design. 


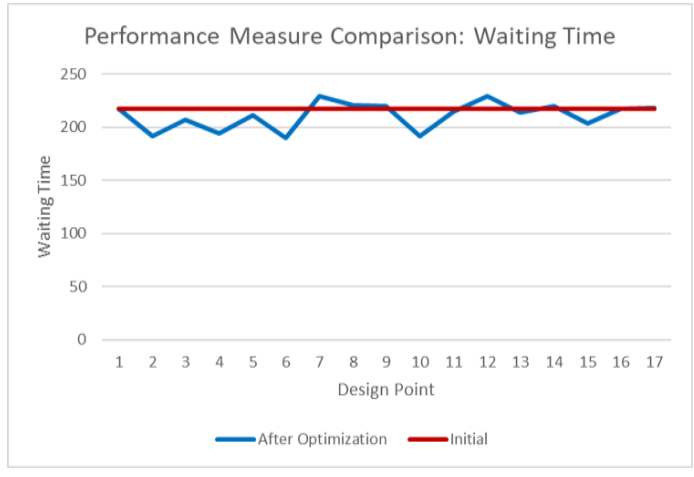

Figure 6 Waiting Time Comparison

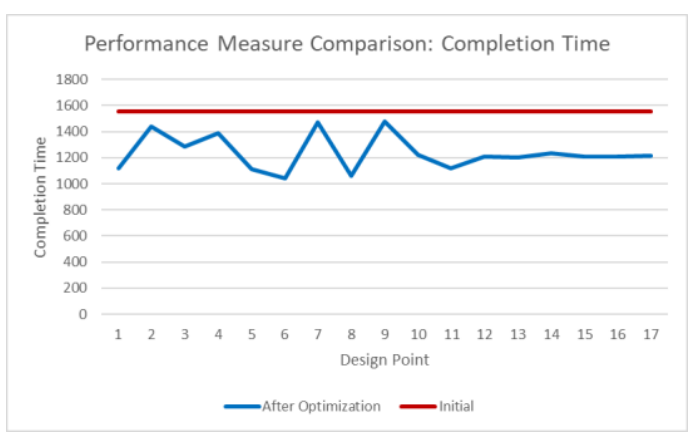

Figure 7 Completion Time Comparison

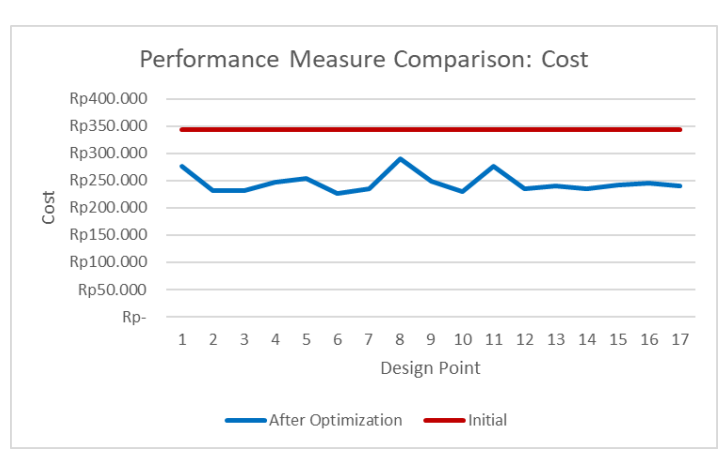

Figure 8 Completion Time Comparison

\section{CONCLUSION}

In this research, simulation is used to replicate real world system happening in the hospital, especially on the waste handling system. Since waste handling system consists of complex activities and rules, DES is combined with $\mathrm{ABM}$ to give better sense in how the system behaves and performs under certain condition. Multi-agent approach as an enhancement of the widely used a single model process.

Optimization result shows that there is 17 unique efficient design points. Result shows that DP6 performs best in every performance measure, reducing waiting time 26.87 minutes, reducing completion time 506.8285 minutes, and reducing cost of IDR 117,144 . Increasing resource level of cleaning service staff and incinerator operators is the solution in eliminating resource deadlock occurred in X1 and X2 and inefficiency in the system.
However, higher variation in the design point and higher number of individuals in the Genetic Algorithm steps could potentially bring up another local optima or even global optima. Potential future work related to this issue could be including indirect costs to calculate overall system cost, hence contributing in identifying biggest cost consumption and bottlenecks more accurately.

\section{AUTHORS CONTRIBUTIONS}

Danica Virlianda Marsha: study concept or design, data collection, writing the paper. Riyanarto Sarno: supervising. Kelly Rossa Sungkono: study concept, critical revised article.

\section{ACKNOWLEDGMENTS}

This research was funded by Lembaga Pengelola Dana Pendidikan (LPDP) under Riset Inovatif-Produktif (RISPRO) Invitation Program, and the Indonesian Ministry of Education and Culture under Penelitian Terapan Unggulan Perguruan Tinggi (PTUPT) Program managed by Institut Teknologi Sepuluh Nopember (ITS).

\section{REFERENCES}

[1] WHO, "Critical preparedness, readiness and response actions for COVID-19: WHO/2019nCoV/Community_Actions/2020.3," no. March, pp. 1-3, 2020, [Online]. Available: https://www.who.int/publications-detail/criticalpreparedness-readiness-and-response-actionsfor-covid-19.

[2] L. Bedoya-Valencia and E. Kirac, "Evaluating alternative resource allocation in an emergency department using discrete event simulation," Simulation, vol. 92, no. 12, pp. 1041-1051, 2016, doi: 10.1177/0037549716673150.

[3] S. Lidberg, T. Aslam, L. Pehrsson, and A. H. C. $\mathrm{Ng}$, "Optimizing real-world factory flows using aggregated discrete event simulation modelling: Creating decision-support through simulationbased optimization and knowledge-extraction," Flexible Services and Manufacturing Journal, vol. 32, no. 4, pp. 888-912, 2020, doi: 10.1007/s10696-019-09362-7.

[4] S. I. Sabilla, R. Sarno, and Y. A. Effendi, "Optimizing time and cost using goal programming and FMS scheduling," 2018 International Conference on Information and Communications Technology, ICOIACT 2018, vol. 2018-Janua, pp. 244-249, 2018, doi: 10.1109/ICOIACT.2018.8350727.

[5] T. Ahmed, S. M. Hossain, and M. A. Hossain, "Reducing completion time and optimizing 
resource use of resource-constrained construction operation by means of simulation modeling," International Journal of Construction Management, vol. 0, no. 0, pp. 112, 2018, doi: $10.1080 / 15623599.2018 .1543109$.

[6] R. Z. Farahani and M. Elahipanah, "A genetic algorithm to optimize the total cost and service level for just-in-time distribution in a supply chain," International Journal of Production Economics, vol. 111, no. 2, pp. 229-243, 2008, doi: 10.1016/j.ijpe.2006.11.028.

[7] K. Ghanes et al., "Simulation-based optimization of staffing levels in an emergency department," Simulation, vol. 91, no. 10, pp. 942-953, 2015 $10.1177 / 0037549715606808$.

[8] A. Bahari and F. Asadi, "A simulation optimization approach for resource allocation in an emergency department healthcare unit," Global Heart, vol. 15, no. 1, pp. 1-6, 2020, doi: 10.5334/GH.528.

[9] M. Yousefi, M. Yousefi, and F. S. Fogliatto, "Simulation-based optimization methods applied in hospital emergency departments: A systematic review," Simulation, vol. 96, no. 10, pp. 2020, 291-806, doi: $10.1177 / 0037549720944483$.

[10] E. Cabrera, M. Taboada, M. L. Iglesias, F. Epelde, and E. Luque, "Simulation optimization for healthcare emergency departments," Procedia Computer Science, vol. 9, no. December, pp. 1464-1473, 2012, doi: 10.1016/j.procs.2012.04.161.

[11] P. Devapriya et al., "StratBAM: A DiscreteEvent Simulation Model to Support Strategic Hospital Bed Capacity Decisions," Journal of Medical Systems, vol. 39, no. 10, 2015, doi: 10.1007/s10916-015-0325-0.

[12] L. B. Holm, H. Lurås, and F. A. Dahl, "Improving hospital bed utilisation through simulation and optimisation. With application to a $40 \%$ increase in patient volume in a Norwegian general hospital," International Journal of Medical Informatics, vol. 82, no. 2, pp. $\quad 80-89, \quad 2013, \quad$ doi: 10.1016/j.ijmedinf.2012.05.006.

[13] H. Zhang, T. J. Best, A. Chivu, and D. O. Meltzer, "Simulation-based optimization to improve hospital patient assignment to physicians and clinical units," Health Care Management Science, vol. 23, no. 1, pp. 117141, 2020, doi: 10.1007/s10729-019-09483-3.

[14] K. R. Sungkono and R. Sarno, "Constructing control-flow patterns containing invisible task and non-free choice based on declarative model," International Journal of Innovative Computing, Information and Control, vol. 14, no. 4, pp. 1285-1299, 2018, doi: 10.24507/ijicic.14.04.1285.

[15] F. Klügl and A. L. C. Bazzan, "Agent-based modeling and simulation," AI Magazine, vol. 33, no. 3, pp. 29-40, 2012, doi: 10.1609/aimag.v33i3.2425.

[16] D. Goldberg, "Genetic Algorithms in Search," Optimization and Machine Learning, 1989.

[17] S. Hossain, S. Mahmud, and M. Hossain, "Multi-Objective Linear Programming for Project Time-Cost Optimization by Fuzzy Goal Programming with Genetic Algorithm," vol. 4, no. 1, pp. 163-178, 2016.

[18] X. Ros-Roca, L. Montero, and J. Barceló, "Notes on Using Simulation-Optimization Techniques in Traffic Simulation," Transportation Research Procedia, vol. 27, pp. 881-888, 2017, doi 10.1016/j.trpro.2017.12.098.

[19] Y. Mulya, "Inventory simulation-optimization model for small business," International Journal of Business, Economics, and Social Development, vol. 1, no. 2, pp. 55-60, 2020, doi: 10.46336/ijbesd.v1i2.36.

[20] D. Muravev, H. Hu, A. Rakhmangulov, and P. Mishkurov, "Multi-agent optimization of the intermodal terminal main parameters by using AnyLogic simulation platform: Case study on the Ningbo-Zhoushan Port," International Journal of Information Management, vol. 57, no. April, p. 102133, 2021, doi: 10.1016/j.ijinfomgt.2020.102133.

[21] K. Katsaliaki and N. Mustafee, "Applications of simulation within the healthcare context," Journal of the Operational Research Society, vol. 62, no. 8, pp. 1431-1451, 2011, doi: 10.1057 jors.2010.20.

[22] J. Viana, T. B. Simonsen, F. A. Dahl, and K. Flo, "A hybrid discrete event agent based overdue pregnancy outpatient clinic simulation model," Proceedings - Winter Simulation Conference, vol. 2018-Decem, pp. 1488-1499, 2019, doi: 10.1109/WSC.2018.8632282.

[23] A. T. Nguyen, S. Reiter, and P. Rigo, "A review on simulation-based optimization methods applied to building performance analysis," Applied Energy, vol. 113, no. January, pp. 1043-1058, 2014, doi: 10.1016/j.apenergy.2013.08.061. 
[24] Y. W. Si, V. I. Chan, M. Dumas, and D. Zhang, "A Petri Nets based Generic Genetic Algorithm framework for resource optimization in business processes," Simulation Modelling Practice and Theory, vol. 86, no. April 2017, pp. 72-101, 2018, doi: 10.1016/j.simpat.2018.05.004.

[25] G. I. Budiawati and R. Sarno, "Time and cost optimization of business process RMA using PERT and goal programming," Telkomnika (Telecommunication Computing Electronics and Control), 2019, doi: 10.12928/TELKOMNIKA.v17i2.11792.

[26] B. Meidyani, R. Sarno, and A. L. Nurlaili, "Time and cost optimization using scheduling job shop and linear goal programming model," 2018 International Conference on Information and Communications Technology, ICOIACT 2018, vol. 2018-Janua, pp. 555-560, 2018, doi: 10.1109/ICOIACT.2018.8350720.

[27] A. Fajar and R. Sarno, "Asynchronous agentbased simulation and optimization of parallel business," Telkomnika (Telecommunication Computing Electronics and Control), vol. 17, no. 4, pp. 1731-1739, 2019, doi: 10.12928/TELKOMNIKA.v17i4.10846.

[28] G. Mantzaras and E. A. Voudrias, "An optimization model for collection, haul, transfer, treatment and disposal of infectious medical waste: Application to a Greek region," Waste Management, vol. 69, pp. 518-534, 2017, doi: 10.1016/j.wasman.2017.08.037.

[29] H. Aghassi, S. N. Abadi, and E. Roghanian, "A Multi-objective Genetic Algorithm for Optimization Time-Cost Trade-off Scheduling," no. 1 , pp. 356-359, 2012.

[30] C. B. Morgan, J. Banks, and J. S. Carson, "Discrete-Event System Simulation," Technometrics, 1984, doi: 10.2307/1268124.

[31] A. T. Rahman, R. Sarno, and Y. A. Effendi, "Goal programming to optimize time and cost for each activity in port container handling," 2018 International Conference on Information and Communications Technology, ICOIACT 2018, vol. 2018-Janua, pp. 866-871, 2018, doi: 10.1109/ICOIACT.2018.8350808.

[32] M. R. Bintang, K. R. Sungkono, and R. Sarno, "Time and cost optimization in feasibility test of CCTV project using CPM and PERT," 2019 International Conference on Information and Communications Technology, ICOIACT 2019, pp. 678-683, 2019, doi: 10.1109/ICOIACT46704.2019.8938466.

[33] M. A. P. Subali, R. Sarno, and Y. A. Effendi, "Time and cost optimization using fuzzy goal programming," 2018 International Conference on Information and Communications Technology, ICOIACT 2018, vol. 2018-Janua, no. 1 , pp. 471-476, 2018, doi: 10.1109/ICOIACT.2018.8350723.

[34] R. C. Lin, M. Y. Sir, and K. S. Pasupathy, "Multi-objective simulation optimization using data envelopment analysis and genetic algorithm: Specific application to determining optimal resource levels in surgical services," Omega (United Kingdom), vol. 41, no. 5, pp. 881-892, 2013, doi: 10.1016/j.omega.2012.11.003. 